materials only 20 needed amputations, and no patient lost more than one finger. The clinical cases confirm the experimental findings that paint and anti-rust sealant are not as tissue destructive as hydrocarbon solvents.

This report illustrates the dangers of delaying correct treatment. Local incisions in casualty departments are futile and merely waste precious time. Injection of local anaesthetics into digits increases tissue tension and worsens ischaemia. Although case 1 was decompressed early, the extent of decompression was inadequate. Low viscosity fluids spread into adjacent fingers, the palm, and thence to the dorsum of the hand and up the forearm. If the fluid is highly inflammatory the initial decompression should include adjacent fingers to the one injured (except the thumb, which is usually spared), the palm, the carpal tunnel, and the dorsum of the hand.

The principles of treatment for this type of injury are: (1) urgent referral to an experienced surgeon; (2) decompression of the digit and palm for paint injuries and wider decompression for solvent injuries under general anaesthesia or brachial block with local anaesthetic. A tourniquet should be applied after raising the arm for five minutes and kept on for as short a period as possible. An Esmarch's bandage should not be used as the pressure it exerts disseminates the foreign material further; (3) broad-spectrum antibiotics to prevent secondary infection of devitalised tissue-fortunately most solvents are bactericidal ; (4) tetanus toxoid cover; (5) high doses of steroids, which may help in reducing the inflammatory response ${ }^{18}$; (6) analgesics; (7) very frequent postoperative observation of the hand, so that further decompression may be performed if necessary; and (8) early intensive rehabilitation to prevent stiffness in the digits.

I should like to thank $\mathrm{Mr}$ Basil Helal for advice and permission to report on his cases and Mr A W Hooper of Ziebart Great Britain Ltd for technical help.

\section{References}

Morley, R, British Medical fournal, 1967, 1, 25.

2 Workman, C E, Missouri Medicine, 1963, 60, 856.

3 Blue, A I, and Diristine, M J, Northwest Medicine, 1965, 64, 342.

+ Nahigian, S H, fournal of the American Medical Association, 1966, 195, 176.

5 Stark, H H, Ashworth, C R, and Boyes, J H, fournal of Bone and foint Surgery, 1967, 49A, 637.

${ }^{6}$ Wofford, B H, Southern Medical fournal, 1973, 66, 307.

' Scher, C, Schuh, F D, and Harvin, J S, British fournal of Plastic Surgery, $1973,26,167$.

${ }^{8}$ Burke, P J, and Conolly, W B, Medical fournal of Australia, 1973, 2, 276.

9 Williams, C S, and Riordan, D C, Southern Medical fournal, 1974, 67, 295.

10 Stepanuk, M, jun, fournal of the American Osteopathic Association, 1976, 75, 739.

${ }^{11}$ Kaufman, H D, and Williams, H O, British fournal of Surgery, 1966, 53, 57.

12 Weeks, P M, fournal of Kentucky Medical Association, 1967, 65, 1086.

13 Waters, W R, Penn, I, and Ross, H M, Plastic and Reconstructive Surgery, 1967, 39, 613 .

14 Walton, S, Clinical Orthopaedics and Related Research, 1971, 74, 141

${ }_{15}$ Remark, F L, and Weeks, P M, Missouri Medicine, 1972, 69, 196.

${ }^{16}$ Kaufman, H D, British fournal of Surgery, 1968, 55, 340.

${ }_{17}$ Kaufman, H D, The Hand, 1970, 2, 63.

18 Gillespie, C A, et al, American fournal of Surgery, 1974, 128, 383.

(Accepted 27 September 1977)

\title{
Malaria in Nottingham children
}

\author{
N RUTTER
}

\section{Introduction}

In the past ten years malaria has been increasingly recognised as a hazard of international travel. ${ }^{1-4}$ The World Health Organisation has recently prepared an up-to-date guide ${ }^{5}$ that gives information to travellers on the risks of malaria in various countries and advises on preventive measures, including chemoprophylaxis. Several series of imported malaria in Britain have been reported, ${ }^{6-8}$ all emphasising the importance of a high index of suspicion of the diagnosis in febrile patients who have recently returned from endemic areas, particularly Africa and Asia. There has, however, been no report of imported malaria in children in Britain. To show that early diagnosis and effective prophylaxis are equally important in children, I have reviewed all the recent cases of malaria in Nottingham children. soon after arrival, but in the others the onset of sym toms was delayed by up to nine months. All made an uneventful recovery, although two children with $P$ vivax infections had a further relapse after chloroquine treatment only.

The question "Where have you been?" should be put to all immigrant parents whose children have a febrile illness. Agencies who provide travel for Asian immigrant families returning home for a visit should be encouraged to provide instructions about malaria prophylaxis.

\footnotetext{
Department of Child Health, University Hospital and Medical School, Nottingham NG10 5LL

N RUTTER, MB, MRCP, lecturer in child health
}

\section{Clinical features}

From January 1972 to August 197716 children (11 boys and five girls) were admitted to either Nottingham Children's Hospital or Nottingham City Hospital suffering from malaria. Their ages ranged from 11 months to 10 years-eight children were below school age. Thirteen children had benign tertian malaria ( $P$ vivax), two had malignant tertian malaria ( $P$ falciparum), and in one child the type was not identified.

All the children had immigrant parents, who originated from Pakistan (nine), India (five), Nigeria (one), and Ethiopia (one), although 10 children had been born in Britain. The malaria had been acquired in Pakistan (nine), India (five), and Nigeria (two). Both $P$ falciparum infections had been acquired in Nigeria. The children 
had been visiting these countries for a period ranging from three weeks to six years. Four children had come to England for the first time. Most admissions took place in the spring and summer.

Two children were ill on arrival ( $P$ vivax and $P$ falciparum) and a third child became ill on the day after arrival ( $P$ falciparum). The remaining children with benign tertian malaria developed symptoms at intervals ranging from two weeks to nine months after leaving the endemic area. A referral letter from the general practitioner mentioned malaria as a possible diagnosis in 12 of the 16 cases. The presenting symptoms and signs were: intermittent fever (eight), non-specific fever (eight), vomiting (nine), rigors (10), splenomegaly (10), and hepatomegaly (five).

\section{LABORATORY INVESTIGATIONS}

In all cases malaria was confirmed by examination of a thick or thin blood film. In one case the number of parasites was small and the type could not be identified. Eight children were anaemic on presentation, with a haemoglobin of less than $10 \mathrm{~g} / 100 \mathrm{ml}$. In three cases this was predominantly an iron-deficiency anaemia. One Nigerian boy was found to have glucose-6-phosphate dehydrogenase deficiency. White cell counts ranged from $4 \cdot 2$ to $23 \times 10^{9} / 1\left(4200-23000 / \mathrm{mm}^{3}\right)$ and were not helpful in the diagnosis.

\section{TREATMENT}

All the children were given a short course of chloroquine by mouth in the appropriate recommended dose. In addition 11 children with $P$ vivax infections were given a two-week course of primaquine to eliminate the parasites from the liver and prevent a subsequent relapse. ${ }^{9}$ There were no side effects and all the children recovered uneventfully. Most were discharged home after about three days.

\section{COMPLICATIONS}

Two children, aged 11 months and 7 years, who had $P$ vivax infections and received only suppressive treatment with chloroquine relapsed with a further confirmed infection two months later and needed a second course of treatment.

A 3-year-old Nigerian boy developed malignant tertian malaria the day after returning to England from a three-week holiday in Nigeria. Apart from a fever the only abnormal finding was pallor. His haemoglobin was $6 \mathrm{~g} / 100 \mathrm{ml}$ with a deficiency of glucose-6phosphate dehydrogenase. The anaemia improved when the malaria was treated.

An 11-month-old Pakistani boy developed benign tertian malaria two weeks after arrival in England for the first time. Subsequent investigation showed intestinal infestation with Ascaris lumbricoides, Hymenolepis nana, and Giardia lamblia, which was treated.

\section{Discussion}

The incidence of malaria in England and Wales is increasing, a result of an increase in travel to endemic areas (see figure). Of 1162 reported cases in $1976,319\left(27^{\circ}{ }^{\circ}\right)$ were children under the age of 15 years. Most Nottingham children acquired their infection in Pakistan or India. Most were born in England but had been to Asia for a holiday or extended visit. Increasingly, Asian immigrants now tend to return to Pakistan or India for some weeks or months, taking their families with them. The parents may still have some natural immunity to malaria but their children have none. There is likely therefore to be an increasing number of children in Britain with imported malaria, particularly caused by $P$ vivax, which is common in some areas of Pakistan. The Asian immigrant population in Nottingham is small compared with other British cities. In the 1971 census there were 1790 Pakistani-born and 2250 Indian-born residents out of a population of 300630 .

The illness itself in the children studied was characterised by fever, often with vomiting and rigors. The fever was not always intermittent, neither was splenomegaly always present. Reassuringly over half the children were correctly diagnosed by their

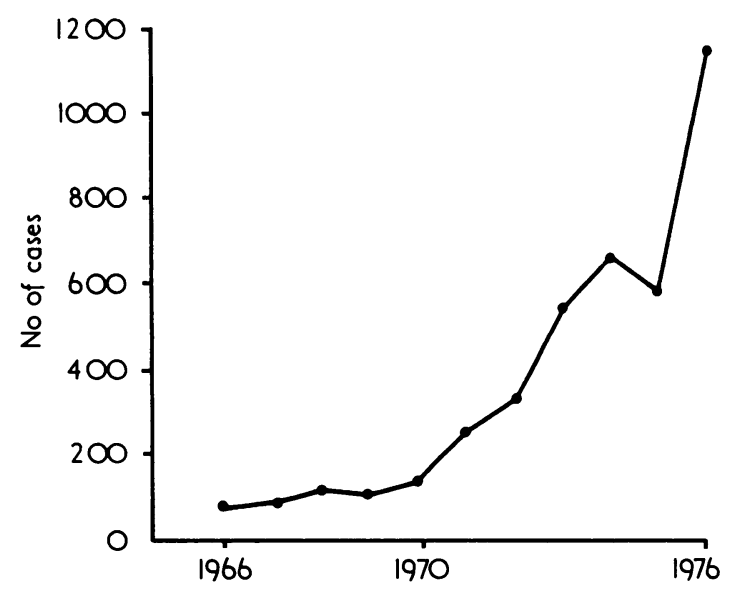

Incidence of malaria in England and Wales, 1966-76.

general practitioners. Since the illness is unremarkable when compared with the usual febrile illnesses of childhood, the question "Where have you been ?" should always be put to immigrant parents whose children have a febrile illness, particularly if there is no obvious cause for the fever. This study confirms other reports that benign tertian malaria may present several months after the patient has left an endemic area. Treatment with a short course of chloroquine is effective. Two of the children had a relapse after receiving chloroquine treatment only. It is mandatory to prescribe a two-week course of primaquine in children with $P$ vivax infections to prevent relapses if the fanily intends to remain in Britain. ${ }^{10}$

It is unrealistic to put the responsibility for protection against malaria on to the individual " because he does not have the necessary information and is unlikely to seek it. The travel agencies who arrange travel to endemic areas, particularly those dealing with flights to Pakistan and India for immigrant families, should be encouraged to warn prospective travellers of the risks of malaria and advise them to consult their doctor about chemoprophylaxis.

\section{References}

${ }^{1}$ British Medical fournal, 1969, 2, 776.

2 British Medical fournal, 1972, 2, 604

${ }^{3}$ British Medical fournal, 1973, 1, 691.

- British Medical fournal, 1976, 4, 1215.

5 World Health Organisation, Information on Malaria Risks for International Travellers, Weekly Epidemiological Record, 1976, 51, 181.

${ }^{6}$ Carswell, J, and Stevenson, D J D, Scottish Medical fournal, 1971, 16, 250.

7 Ansdell, V E, et al, British Medical fournal, 1974, 2, 206. :

${ }^{8}$ Bruce-Chwatt, L J, Southgate, B A, and Draper, C C, British Medical fournal, 1974, 2, 707.

${ }^{9}$ Gilles, H M, British Medical fournal, 1966, 2, 1375.

10 Gilles, H M, Medicine (London), 1974, No 26, 1522.

11 Maegraith, B, British Medical fournal, 1974, 3, 252.

(Accepted 27 September 1977)

WORDS Close to the heart lies the DIAPHRAGM, and close was its supposed function. Initially it was regarded by the Greeks as the seat of the soul, and later of the mind-that is, the organ of thinking rather than feeling. They had two words for diaphragm: diaphragma and phren. Diaphragma seems to have referred to its anatomy ( $\mathrm{G}$ dia, across; phragma, partition); a partition separating the contents of thorax and abdomen, while phren seems to have referred to its function of thinking. We still use phren in anatomical terminology; costophrenic and cardiophrenic angles and phrenic nerve. The concept of phrenic pertaining to the mind persists today in frenetic, frantic, and frenzy-all to do with wild excitement rather than sober thought. The root was revived by Franz Josef Gall in the late eighteenth century when he coined the term phrenology, a pseudo-science that was practised until the early years of the present century. 